\title{
La sociedad de autores españoles (1899-1932)
}

\author{
Raquel SÁnchez García
}

\begin{abstract}
RESUMEN ABSTRACT
Durante la última parte del siglo XIX los autores españoles iniciaron un movimiento asociativo en defensa de sus derechos como profesionales. El proceso culminó en la fundación de la

Sociedad de Autores Españoles (precedente de la actual Sociedad General de Autores Españoles). El objetivo principal de la SAE fue conseguir para los autores la administración y gestión de los derechos derivados de sus composiciones musicales y teatrales, to que tuvo una gran importancia en

un momento en que se estaban transformando las formas de ocio en nuestro país. Estas páginas pretenden llevar a cabo un repaso de su organización, sus logros y su evolución desde 1899 hasta 1932.

PALABRAS CLAVE: Sociedad de Autores Españoles. Escritores. Músicos. Espectáculos. Historia Cultural.

During the last part of XIX century, Spanish authors started a movement looking after their rights as professionals in pursuit of associations to defend them. The process finished in the foundation of the Sociedad de Autores Españoles (precedent of the $S G A E)$. The principal objective of the $S A E$ was to obtain the right to manage and to negotiate their own works and compositions. This was a very important sucess because of the change of leisure in Spain. In these pages, I will try to study the organization, the achievements and the evolution of the SAE from 1899 to 1932.

\section{KEY WORDS}

Sociedad de Autores Españoles. Writers. Musicians. Shows. Cultural History.
\end{abstract}


Durante el siglo XIx, la situación del autor como profesional se fue configurando poco a poco ${ }^{1}$. Generalmente, el escritor no podía encargarse de la publicación de sus propias obras, por lo que con frecuencia recurría a acuerdos más o menos formales con impresores y editores, acuerdos que se regularon un tanto con el reconocimiento legal de la propiedad intelectual que había traído consigo la ley de $1847^{2}$. Sin embargo, los autores quedaban, en la mayoría de los casos, en inferioridad de condiciones con respecto a los editores e insuficientemente pagados, por lo que ya antes de la ley de 1847 trataron de organizarse para constituir sociedades que publicaran sus obras. La más interesante de estas iniciativas fue la Sociedad de Autores Dramáticos, creada en 1844 por los más famosos autores teatrales del momento, entre ellos el Duque de Rivas, Bretón de los Herreros, Tomás Rubí, Leopoldo Augusto de Cueto, Patricio de la Escosura, Juan Eugenio Hartzenbusch, José María Díaz, Carlos García Doncel, Luis Olona, Luis Valladares y Antonio Gil y Zárate. No es de extrañar que se tratara en su gran mayoría de autores teatrales, pues el teatro, al producir importantes beneficios económicos, era una de las pocas ramas del arte que resultaba rentable, de ahí que los autores estuvieran especialmente interesados en defender su fuente de beneficio y en evitar a toda costa que ésta cayera en manos de los editores, como sucedió con el famoso caso de Don Juan Tenorio de Zorrilla y el editor Delgado, a quien el poeta vendió la obra en uno de sus frecuentes momentos de necesidad económica, perdiendo una enorme cantidad de dinero ${ }^{3}$.

Sin embargo, esta iniciativa no resultó muy productiva y la mayoría de los escritores, sobre todo los que no se dedicaban al teatro, tenían que vender sus producciones a distintos empresarios que después se encargaban de su publicación, en el caso de libros, o de su copia y posterior alquiler cuando se trataba de libretos y partituras musicales. Las condiciones de los contratos no eran en absoluto favorables para los autores, quienes solían vender todos sus derechos sobre las obras, es decir, la propiedad

1 El presente trabajo forma parte de un estudio sobre el mundo editorial y literario en Madrid (1900-1931) para el cual la autora ha recibido una beca postdoctoral financiada por la Comunidad de Madrid y la Unión Europea. Dicho estudio se encuadra en el proyecto de investigación «Historia de la edición española contemporánea, 1836-1936», dirigido por Jesús A. Martínez Martín y realizado en el Departamento de Historia Contemporánea, Facultad de Geografía e Historia (Universidad Complutense de Madrid).

2 Vid. Raquel SÁNCHEZ GARCÍA, «La propiedad intelectual en España, 1847-1936», en Hispania, CSIC, en prensa.

3 Doy las gracias a Jesús A. Martínez Martín por la información que me ha proporcionado a este respecto, parte de la cual puede encontrarse en su texto «El mercado editorial y los autores. El editor Delgado y los contratos de edición", en Actas del Congreso Écrire en Espagne, CNRSENS, Saint-Cloud (en prensa). 
absoluta de las mismas por cantidades que no eran muy altas. Con frecuencia, los autores solían escribir a cuenta, mediante anticipos de obras que estaban redactando o iban a redactar. Eso les permitió a algunos salvar situaciones económicas críticas, aunque trajo como contrapartida una total dependencia de su «editor-banquero».

Los compradores de este tipo de obras no siempre eran editores, a veces se trataba de simples particulares que se hacían con la propiedad literaria de un autor como forma de inversión, adquiriendo los derechos sobre una obra de un autor español, o los derechos de traducción de obras de autores extranjeros. Con frecuencia, estos compradores vendían a su vez a editores especializados, con los que establecían contratos de explotación conjunta de algunas obras, o vendían totalmente sus derechos, obteniendo a cambio una cantidad por derecho de representación. Ejemplos de este tipo de contratos los tenemos, por ejemplo, en el firmado entre Fernando Navarro y Martín a favor de Ricardo García y Martínez, a quien vendió los derechos de zarzuelas como El grumete, o de óperas como II trovatore y Bocanegra de Verdi ${ }^{4}$. Esta situación se fue generalizando en la última parte del siglo XIX, y los autores, especialmente los de teatro y los libretistas, fueron vendiendo sus obras a un grupo de editores cada vez más reducido, que fue poco a poco copando el mercado. Se trataba de editores que garantizaban un pago pronto y seguro, y que formaron lo que en la época se llamaba "galerías líricas", que eran las propietarias de esias obras, y a las que había que pagar un canon si se quería representar dichas composiciones. Así sucedió a Jackson Veyán, quien cedió tres obras (A gusto de los papás, La llave del destino y Una limosna, por Dios) a Enrique Larrumbe y Arregui, editor de la Biblioteca Lírico-Dramática, por 500 pesetas, reservándose los derechos de representación ${ }^{5}$. Lo mismo hizo Javier de Burgos al vender varias composiciones a Eduardo Hidalgo (de la Administración Lírico-Dramática). El contrato, firmado el 10 de marzo de 1886, señalaba que Burgos: «...cede a perpetuidad en absoluto y sin reserva alguna» estas obras por 2.500 pesetas, con el compromiso de abstenerse a hacer ningún cambio en dichas obras sin el consentimientos de Hidalgo ${ }^{6}$. Los compositores salían mejor parados, pues la legislación reconocía más claramente sus derechos, pero para poder representar sus partituras, necesitaban de copistas

\footnotetext{
4 Archivo Histórico de Protocolos Notariales (AHPN), protocolo 35.332, fechado el 3 de noviembre de 1884. Navarro Martín cedió la mitad de los derechos de reproducción y propiedad de estas obras.

AHPN, protocolo 34.708 ; fechado el 14 de octubre de 1880

AHPN, protocolo 35.623 .
} 
que pudieran ofrecerlas a las diversas compañías de teatro y variedades. La figura del copista llegó a alcanzar tal importancia que en sus manos estaba la misma difusión de las obras, pues podía negarse a copiar una partitura si ésta no había obtenido un gran éxito en su primera representación.

Los compositores y autores se encontraban, pues, atados de pies y manos, y pocas eran las posibilidades de gestionar su producción artística. En este contexto, Florencio Fiscowich y Díaz de Antoñana tuvo la idea de comprar, a perpetuidad, a los compositores el derecho de copia y de reproducción de los materiales de orquesta. Fiscowich adquirió los derechos sobre las obras que ya habían compuesto y sobre las que compondrían en el futuro, remunerándoles como nunca hasta el momento ningún copista había pagado a los músicos. En aquel momento, Florencio Fiscowich era un joven editor que había heredado una de las galerías dramáticas más famosas: Alonso Gullón e Hijos, en la que había trabajado como gerente. Ya en esta sociedad, Fiscowich se había hecho con una importante cantidad de obras dramáticas y sobre todo musicales pertenecientes a otro editor, Ricardo Puente y Braña, que tenía deudas con Gullón e Hijos ? La estrategia de Fiscowich fue enormemente exitosa para él, pues los autores, cansados de las arbitrariedades y tacañería de los copistas, acudieron raudos a venderle sus obras, de tal manera que su archivo musical acabó convirtiéndose en el más importante de los existentes, monopolizando, por tanto, el alquiler de materiales de orquesta. Si tenemos en cuenta, además, la densidad de la vida teatral de la España de la época ${ }^{8}$, nos podemos hacer una idea del poder que llegó a tener Fiscowich. Únicamente Ruperto Chapí fue consciente de la trampa que para compositores y compañías significaba la exclusiva otorgada a Fiscowich, pero eso será objeto de análisis posterior, y origen de la Sociedad de Autores. Antes resultaría interesante realizar un pequeño esbozo del movimiento asociativo y reivindicativo de autores y compositores.

Antes de la fundación de la Sociedad de Autores Españoles habían surgido otras asociaciones que tuvieron por objeto la defensa de determinados sectores del gremio o de algunos aspectos que los compositores y autores consideraban perjudiciales para sus derechos. Para procurar un primer sistema de previsión social había sido creada en 1872 la Asocia-

\footnotetext{
7 AHPN, protocolo 34.729, escritura de compra-venta fechada en Madrid el 11 de septiembre de 1880 .

8 A. Amorós, Luces de candilejas. Los espectáculos en España (1898-1939), Madrid 1991. pág. 70. Amorós hace esta observación refiriéndose a la cantidad de teatros y a la popularidad de autores, actores y cantantes.
} 
ción de Escritores y Artistas Españoles ${ }^{9}$. Con otro carácter nació la Sociedad Lírico-Española, que en 1881 decidió encargarse de la gestión económica del Teatro Apolo y que, a la larga, resultó un fracaso. Los autores, por su parte, celebraron en 1890 una primera reunión (el llamado Círculo Literario) que tuvo como objetivo reivindicar su parte en la recaudación de los teatros, especialmente por lo que respecta a América. Se nombró presidente a Emilio Sánchez Pastor y entraron en la junta directiva personajes que más adelante desempeñarían un destacado papel en la fundación de la Sociedad de Autores: Chapí, Ramos Carrión, Vital Aza, Echegaray, Ducazcal, Manzano y Monasterio. En 1892 se fundó la Sociedad de Autores, Compositores y Editores de Música que pretendía, imitando a la francesa Société du Petit Droit, cobrar su parte correspondiente de los derechos de ejecución de obras y fragmentos musicales en lugares públicos, como los diversos locales (tabernas, cafés, bailes, salones, etc) y las plazas de toros. A esta sociedad pertenecían, como es lógico, tanto los músicos como los compradores de sus obras, y entre ellos, el ya mencionado Florencio Fiscowich, quien para esos años ya casi era el dueño del mercado, salvo el caso de algunos propietarios aislados, como Luis Aruej (co-propietario del Teatro Apolo) y los Hijos de Hidalgo. Más tarde, esta sociedad se convertiría en la Asociación Lírico-Dramática, germen de la Sociedad de Autores ${ }^{10}$.

\section{CREACIÓN DE LA SOCIEDAD DE AUTORES ESPAÑOLES}

En el origen de la Sociedad de Autores Españoles hay un personaje que personifica como nadie la lucha de los músicos y autores por gestionar sus intereses. Ese personaje no es otro que Sinesio Delgado ${ }^{11}$. En 1898 , tras quince años de trabajo en el periódico Madrid Cómico, Delgado decide abandonarlo y lanzarse a una nueva aventura: la secretaría de la Asociación Lírico-Dramática. Sinesio Delgado tenía una larga experiencia

Vid. J.-F. BotreL, «Sobre la condición de escritor en la España del siglo Xix: la constitución de la Asociación de Escritores y Artistas Españoles (1872-1877)", en M. TUÑ́N DE LARA y J.-F. BoTREL (eds.) Movimiento obrero, política y literatura en la España contemporánea, Cuadernos para el Diálogo, Madrid 1974, págs. 179-210.

10 Acerca de todo este proceso y de los primeros años de la SAE, vid. J. TUSELL, A. DELGADo Porras y M. ${ }^{a}$ L. GonzÁlez PeÑA, La fuerza de la creación. Cien años de la Sociedad General de Autores de España, SGAE, Madrid 2000.

11 Sobre Sinesio Delgado y la creación de la SAE véase su obra Mi teatro. Cómo nació la Sociedad de Autores Españoles, reeditada por la SGAE (Madrid 1999) y el estudio preliminar de M. ${ }^{\text {a }}$ Luz González Peña. Contamos además con el librito de Alberto Delgado. Sinesio Delgado y su obra. Ensayo sobre el escritor que fundó la SAE, Madrid 1962. 
en el mundo de la literatura y la música, pues aparte de su labor en el Madrid Cómico, había sido letrista de diversas composiciones que fueron representadas con diverso éxito. Inmerso como estaba en ese mundo, Delgado sabía de la situación, a veces crítica, en la que con frecuencia se hallaban muchos autores, los cuales, aguzados por la necesidad, vendían sus composiciones y perdían sus derechos sobre las mismas. Había observado la valiente actitud de Ruperto Chapí, quien se había negado a vender sus obras a Fiscowich cuando la mayoría de los autores le habían cedido sus derechos por una cantidad que, si bien superaba a la de otros editores, les impedía obtener rendimientos mayores si sus obras tenían éxito. Generalmente, el problema estribaba en que los autores no se reconocían como profesionales, sino que delegaban la gestión de sus asuntos en otras personas. El proceso que condujo a la fundación de la Sociedad de Autores Españoles fue también el proceso por el que se fue asentando en la mente de los compositores y autores un sentido más profundo de lo que significaba la profesionalización en su campo. Debido a esto, el ejemplo de Chapí no fue comprendido por sus propios compañeros, quienes consideraban una locura su actitud. Chapí contaba con un prestigio profesional y una energía que le permitieron enfrentarse durante seis años a situaciones críticas, como el hecho de que se le negara el estreno de sus obras en muchos teatros. Aún así, supuso un punto de inflexión para el resto de los autores, pues mostró bien a las claras que era posible la independencia de los autores y compositores.

Sinesio Delgado, cuyo entusiasmo igualaba a la energía de Chapí, trató de conseguir que los autores encomendasen la administración de sus obras a la junta directiva de la Sociedad de Autores, Compositores y Editores de Música, cancelando sus contratos con los editores particulares como Fiscowich. Sin embargo, ninguno de ellos quiso aceptar la arriesgada propuesta. Ante esta situación, Sinesio Delgado decidió ser él el primero que diera el paso, y para ello se dispuso a poner término a los contratos que mantenía con los empresarios y traspasó sus obras a la Sociedad mencionada, cuya representación fue aceptada por la Junta directiva en las personas de Ruperto Chapí y Eusebio Sierra. De este modo, Sinesio Delgado se convirtió en el primer autor español cuya obra estaba siendo gestionada por una sociedad formada por autores y compositores de música. Una vez más, su actitud fue considerada un desatino. Como periodista que era, Delgado sabíá el poder de los periódicos para difundir estados de opinión entre el público, por lo que se decidió a lanzar una campaña de prensa en la que poner a debate distintos asuntos clave en el discurrir de la vida del autor, entre ellos la validez de los archivos musicales, la reivindicación de los derechos de los autores, la recaudación en 
América. No fue, precisamente, muy exitosa su campaña, sobre todo por la extrañeza que provocaban sus reclamaciones. Se interpretó su actitud como la de un autor fracasado que trataba de compensar su frustración. Muy destacada resultó la reacción de los editores, quienes como es de imaginar, se opusieron tenazmente a las acciones de Delgado.

Sin embargo, algunos autores que habían sido tratados con desdén por sus empresarios y editores acudieron a la Sociedad de Autores, Compositores y Editores de Música buscando amparo. Se celebró una reunión para tratar este asunto y en ella Ruperto Chapí sugirió que los autores tomasen la misma decisión que Sinesio Delgado, es decir, que abandonasen a sus editores y se uniesen formando una sociedad compacta para defender y administrar sus derechos. Para ello, señalaba Chapí, era necesario reorganizar la sociedad existente y convertirla en un útil instrumento para los autores y compositores mediante la redacción de unos nuevos estatutos. La propuesta tuvo aceptación y el 16 de junio de 1899 se firmó ante notario la escritura que daba nacimiento a la Sociedad de Autores Españoles. Firmaron ante el notario Antonio Turón los siguientes autores y músicos: Vital Aza, Carlos Arniches, Ruperto Chapí, Sinesio Delgado, José Francos Rodríguez, José López Silva, Tomás López Torregrosa, Miguel Ramos Carrión, Eugenio Sellés, Eusebio Sierra y Joaquín Valverde y Sanjuán. Más adelante se unieron Federico Chueca, Tomás Bretón, Tomás Luceño y Serafín y Joaquín Álvarez Quintero. La primera junta directiva se constituyó con Vital Aza como presidente, Sinesio Delgado como secretario, y Ruperto Chapí, Miguel Ramos Carrión, Carlos Arniches, Serafín Álvarez Quintero y Joaquín Valverde y Sanjuán como vocales. Aunque la SAE nació con grandes expectativas, el proyecto que tenía Sinesio Delgado era de mayor alcance aún. Delgado pretendía unir a todas las asociaciones que tuvieran relación con la literatura, el teatro, la música y le periodismo ${ }^{12}$.

La intención de la flamante Sociedad de Autores Españoles (SAE) fue mejorar la situación de sus socios con respecto a la condiciones en la que se hallaban con los editores. La Sociedad iba a cobrar el $8 \%$ de la recaudación de los autores en provincias, el $15 \%$ en el extranjero y el $2 \%$ del pequeño derecho, es decir, de lo recaudado por la ejecución de piezas musicales en lugares públicos (el derecho de ejecución). Así, el autor obtenía un 7\% más de lo que los editores le daban de lo recaudado en provincias, y un $5 \%$ más de lo recaudado en el extranjero.

12 S. Delgado, Mi teatro, pág. 264. 
Para lograr sus propósitos, la Sociedad de Autores contaba con un gran obstáculo: la existencia del archivo único en manos de Florencio Fiscowich, quien alquilaba a los empresarios de teatro los materiales de orquesta. Evidentemente, era necesario llegar a un acuerdo con Fiscowich para que les vendiese su archivo, restituyendo la propiedad de las obras a sus autores para que a su vez éstos cediesen la administración de las mismas a la SAE. La cosa no se presentaba nada fácil. El editor pidió a la Sociedad la cantidad de 2.000.000 pesetas. La Sociedad, representada por Sinesio Delgado y José López Silva, no disponía de esa suma, pero conminó a Fiscowich a redactar el contrato de compra-venta. Fiscowich no debió tomar muy en serio esta propuesta, por lo que, a pesar de que se había comprometido a redactar dicho contrato, ignoró a los autores. Mientras tanto, y para dar más impulso a la SAE, Ruperto Chapí se decidió vender a la Sociedad sus propias obras para siempre a un precio de 25.000 pesetas anuales y el $5 \%$ del ingreso que la Sociedad obtuviera por el alquiler de dichas composiciones. Chapí podría haber obtenido una cantidad de dinero mucho mayor si hubiera vendido a un empresario como Fiscowich. El archivo de Chapí se unió a las obras de autores no comprometidos aún con editores, y permitió a la Sociedad iniciar la competencia con Fiscowich. Su decisión fue un gran respaldo para la SAE, la cual pudo ofrecer a las compañías de provincia el archivo a razón de 10 pesetas diarias. Además, la SAE se hizo con una litografía para poder reproducir con la mayor rapidez posible las partituras y enviarlas a las compañías que las solicitaran. La litografía recibió el nombre de Ruperto Chapí, y logró abastecer a las compañías con más rapidez de lo que era capaz Fiscowich.

En una reunión celebrada el 4 de junio de 1901, la SAE decidió publicar un acuerdo por el que se obligaba a las compañías a elegir el archivo de la SAE y el de Fiscowich. Según cuenta Delgado, esta propuesta fue una baza que jugó la SAE para tratar de mostrar su fuerza ${ }^{13}$. Se trató además de forzar una situación crítica, para lo cual Manuel Quislant y Tomás Barrera adoptaron los seudónimos de maestros Montero y Montesinos, con los cuales estrenaron varias obras que resultaron tener gran éxito, lo que supuso un apoyo más para la SAE. Las obras fueron Doloretes, El género ínfimo y Los niños llorones que se estrenaron en el Teatro Apolo (julio 1901), de los empresarios Enrique Arregui y Luis Aruej, a los que Delgado tuvo que convencer para que no echaran el cierre durante el mes de julio. Fue ésta otra apuesta más de Delgado, pues si la primera obra (Doloretes)

\footnotetext{
13 S. Delgado, Mi teatro, pág. 120.
} 
hubiera sido un fracaso, el prestigio de la SAE habría quedado por los suelos. Pero como resultó todo lo contrario, la SAE pudo contar con multitud de encargos que le hicieron las compañías para sus giras del verano. Fiscowich creyó que los músicos que habían figurado con seudónimo eran Joaquín Valverde y Vicente Lleó, que estaban comprometidos con él, por lo cual les puso una querella.

Ante estos envites de la SAE, Fiscowich decidió actuar creando una sociedad paralela de autores, que fue conocida como la Contrasociedad, que se reunió por vez primera en el Teatro de la Zarzuela (del cual, por cierto, Fiscowich era empresario) el 12 de junio de 1900. Su nombre oficial fue Asociación de Autores, Compositores y Propietarios de obras teatrales. Dispuso de un consejo de honor, formado por Eusebio Blanco, Benito Pérez Galdós, José Echegaray, Gaspar Núñez de Arce, Luis de Larra, Manuel Fernández Caballero y Manuel del Palacio; de una comisión ejecutiva, compuesta por Jerónimo Jiménez, Julián Romea, Antonio Vives, Carlos Fernández Shaw, Manuel Nieto, Miguel Echegaray, Miguel de Palacios y Mauricio Gullón. Los gerentes fueron Fiscowich y los Hijos de Hidalgo. Una importante fractura se había producido en el mundo de autores y músicos. Pero, poco después, ante diversos reveses sufridos por Fiscowich, como la desestimación de su querella, y el éxito de estrenos teatrales impulsados por la SAE, el desarrollo de la situación conducía irremediablemente a la fusión de las dos sociedades, que se produjo el 1 de octubre de 1901. Por su parte, Fiscowich se vio forzado a vender por fin su archivo a la Sociedad de Autores Españoles. Si en un primer momento había pedido, como se dijo antes, 2.000 .000 pesetas, en 1901 cedió su archivo por 300.000 pesetas.

La compensación total que obtuvo Fiscowich, por el archivo y otros conceptos, fue de 1.000 .000 pesetas; 380.000 recibió Luis Aruej, más 620.000 que le debía la SAE por un préstamo; 500.000 pesetas fueron para los Hijos de Hidalgo, y 100.000 pesetas para Ruperto Chapí. El total pagado fue de 2.600 .000 pesetas, que la Sociedad de Autores había obtenido por la emisión de 5.200 obligaciones de 500 pesetas cada una, con un interés del $7 \%$ amortizables en un plazo máximo de 20 años a partir del 1 de enero de $1902^{14}$.

\footnotetext{
14 «Testimonio literal de una escritura de venta de la propiedad de obras literarias y musicales, créditos y derechos por los Sres. Florencio Fiscowich y Díaz de Antoñana, D. Luis Aruej y Navarro, D. Tomás y D. Eduardo Hidalgo y Martínez y D. Ruperto Chapí y Lorente a favor de la Sociedad de Autores Españoles, expedido en Madrid a 7 de diciembre de 1901, por D. Francisco Moragas y Tejera, Notario y Abogado de los ilustres colegios de esta capital», en Boletín Oficial de la Sociedad de Autores Españoles, mayo de 1903.
} 


\section{ORGANIZACIÓN DE LA SOCIEDAD DE AUTORES ESPAÑOLES}

La SAE tuvo su primera sede en el número 8 de la calle del Florín, domicilio de la Sociedad de Autores, Compositores y Editores de Música. Más adelante, entre agosto y septiembre de 1903, se trasladó la sede a la calle Núñez de Balboa n. ${ }^{\circ}$, hasta que en mayo de 1913, las oficinas se desplazaron a la calle del Prado número 24. Poco antes de su renovación en julio de 1932, la SAE se trasladó a la Plaza de Cánovas.

La Sociedad de Autores elaboró unos estatutos para regirse, que más tarde fueron renovados por la Junta general extraordinaria el día 9 de enero de 1904. En la versión de 1901, el artículo primero establecía los fines de la SAE, señalando su carácter corporativo y haciendo hincapié en aspectos concretos como su deseo de gestionar los derechos de ejecución y representación y la administración de las obras de los socios. En la versión de 1904, el artículo primero también contemplaba otros dos objetivos especialmente interesantes que trataban de proteger a los autores y compositores. Uno de ellos era la creación de un montepío en beneficio de los socios necesitados o de sus viudas, hijos y parientes. El otro era la organización de una caja de pensiones para proteger el retiro y la vejez de los socios que lo necesitasen. Ambos proyectos se llevaron adelante. Se establecieron unas cuotas para los socios, cuotas que tenían como objetivo constituir dichos fondos, a los que además se contribuía con dinero sobrante después del pago de todas las obligaciones de la Sociedad, es decir, con parte del dinero que constituía el fondo social de la organización. Otras aportaciones procedían de donaciones voluntarias de los autores que más éxitos tenían con la representación de sus zarzuelas u obras de teatro ${ }^{15}$.

Con respecto a la base material de la SAE, pilar de su funcionamiento, hay que señalar que estaba formado por el beneficio de la venta y alquiler de materiales de orquesta, el beneficio líquido por recaudación de derechos de las obras adquiridas en propiedad, el importe de los saldos contra los autores (adquiridos para su amortización por la SAE a sus antiguos editores), el beneficio líquido por la administración de las obras de los socios y de los materiales de orquesta, el beneficio líquido por derechos de ejecución no repartibles, el beneficio de la venta de libros de comisión y de

15 Los Estatutos de 1901 fueron reproducidos por el Boletín Oficial de la Sociedad de Autores Españoles, enero de 1903. Los de 1904 fueron publicados por la Sociedad de Autores Españoles, Estatutos sociales reformados aprobados en sesión celebrada por la Junta general extraordinaria en 9 de enero de 1904, Madrid 1907. 
libros por las obras ya mencionadas, la renta por intereses del capital impuesto (hasta que se decidiera su aplicación al pago de las amortizaciones) y en general, todos los ingresos que pudieran producirse por cualquier concepto. Por su parte, la SAE se desentendía de las deudas y obligaciones a las que estuviesen sujetos los bienes y las obras de sus socios ${ }^{16}$.

El primer capítulo establecía una limitación temporal para la permanencia de la Sociedad de Autores, que se fijó en 20 años, el tiempo necesario para poder satisfacer los pagos de las obligaciones contraídas con los accionistas que con sus aportaciones facilitaron el pago a los editores cuando se firmó la escritura de compra de los archivos de Fiscowich, de Aruej y de los Hijos de Hidalgo. Se establecía la cláusula de que si el funcionamiento de la Sociedad era del gusto de sus socios, y había contribuido a mejorar su situación, se prolongaba la existencia de la SAE.

Por lo que se refiere a su funcionamiento interno, la SAE estaba formada en primer lugar, evidentemente, por sus socios. Los estatutos constitutivos, y los reformados de 1904, establecían: «Forman la Sociedad los firmantes de la Escritura de constitución y los adheridos posteriormente hasta la fecha del 5 de octubre de 1901, en que se acordó en Junta general, suspender la admisión de nuevos socios" ${ }^{17}$. La idea primera era beneficiar a los autores que tanto en la fundación de la Sociedad como en los momentos que siguieron hasta la firma de la escritura se arriesgaron comprometiéndose en el proyecto, poniéndose como fecha tope, como dice el artículo mencionado, el 5 de octubre de 1901 (recordemos que la escritura se firmó el 17 de octubre de 1901). Más adelante, y refiriéndose a potenciales socios que se afiliaran con posterioridad a esta fecha, se señaló que "podrán ingresar como socios todo autor, compositor, heredero de autor o compositor o propietario de obras que por cesión o compra, que tenga derechos de autor que recaudar». En este conglomerado se socios, se estableció la diferencia entre ellos de la siguiente forma: «Además de este voto, común a todos los socios, los autores y compositores tendrán derecho a un voto más, por cada suma de dos mil pesetas de recaudación total que hayan alcanzado, por su parte personal de derechos de autor durante el último año natural que haya transcurrido" ${ }^{18}$. La versión de 1904 no transformó, como vemos, la original, a pesar de la petición de un grupo de socios que demandaban «...que se modifiquen los estatutos en el sentido de que la SAE sea tal sociedad, es decir, que todos

16 Sociedad de Autores Españoles, Estatutos sociales...1904..

17 Sociedad de Autores Españoles, Estatutos sociales... 1904..., artículo $42 .^{\circ}$

18 Sociedad de Autores Españoles, Estatutos sociales... 1904..., artículo $46 .^{\circ}$. 
cuantos la componen tengan igualdad de deberes y de derechos dentro de ella». Entre los firmantes se encontraban Galdós, Joaquín Dicenta, Leopoldo Cano, Manuel Linares Rivas y Carlos Fernández Shaw ${ }^{19}$.

Por el artículo 22 de los estatutos constitutivos se obligaba a los socios a formar parte de la SAE por lo menos durante tres años, pasados los cuales podía darse de baja previo aviso (pues era necesario advertir a los representantes). Además, los socios tenían expresamente prohibido firmar cualquier tipo de convenio con ninguna empresa ni rebajar el importe de sus derechos. Igualmente, sólo podían recibir sus ingresos por mediación del director-gerente, jamás por ningún representante. Estas estrictas estipulaciones estatutarias fueron censuradas por muchos autores y compositores (como veremos más adelante), aunque en los primeros momentos de funcionamiento de la SAE alcanzaban pleno sentido, pues era la única forma de garantizar para los autores el cobro íntegro de sus derechos.

Según los estatutos, la SAE se regía por una junta directiva, de la que todos los socios podían formar parte. Estaba formada por cinco autores y dos compositores, que serían elegidos por la Junta general de socios. De entre los seleccionados se nombrarían otros cargos como el de tesorero, presidente y secretario. Los demás serían vocales. La Junta Directiva designaría al director-gerente, que era el encargado de las cuestiones administrativas y de funcionamiento cotidiano de la SAE. Con frecuencia se designaron presidentes honorarios, con una función puramente simbólica, para honrar a figuras especialmente destacadas. Fueron presidentes honorarios, entre otros, Jacinto Benavente y Benito Pérez Galdós. Por último, era obligatoria la celebración anual, durante la segunda quincena del mes de enero, de una Junta General Ordinaria.

\section{FUNCIONAMIENTO DE LA SOCIEDAD DE AUTORES ESPAÑOLES}

A través de los reglamentos y de las publicaciones de la Sociedad, es posible estudiar su funcionamiento cotidiano. Antes de nada, es necesario indicar que la SAE publicó desde 1903 un Boletín Oficial de la Sociedad de Autores Españoles que aparecía mensualmente y que era gratuito para los socios. Por medio de este boletín los socios se informaban de las acciones de la asociación, de los resultados económicos obtenidos y de la compra de derechos para la interpretación de canciones y obras de teatro.

19 Boletín Oficial de la Sociedad de Autores Españoles, diciembre de 1903. 
El Boletín estuvo en funcionamiento hasta 1914, cuando fue sustituido por La Propiedad Intelectual. Revista mensual, órgano de la Sociedad de Autores Españoles. Aunque mantenía su carácter informativo, La Propiedad Intelectual contenía otro tipo de crónicas, como reflexiones acerca del carácter del derecho de propiedad intelectual, reseñas de las acciones de asociaciones afines en el extranjero, el cine y la producción intelectual, o las decisiones gubernamentales que pudiesen afectar al sector ${ }^{20}$.

El reglamento de 1907 establecía el sistema de organización administrativa de la SAE separándolo en las siguientes secciones: correspondencia, contabilidad e intervención, caja, distribución del archivo, copistería y librería. Cada una de estas secciones estaba dirigida por un jefe que contaba con varios auxiliares ${ }^{21}$. Este sistema funcionó hasta los años veinte, momento en que la SAE había alcanzado tal nivel de complejidad que fue necesario reorganizarla. Se habían diversificado las distintas formas de recaudación y habían surgido nuevas expresiones artísticas que obligaban a un replanteamiento del funcionamiento interno de la Sociedad. En 1922 se decidió llevar a cabo una reforma de los reglamentos, quedando instituidas cuatro nuevas secciones:

- Sección de Derechos de Representación, cuyo objeto sería el cobro y administración de los derechos devengados por las obras dramáticas y lírico-dramáticas, así como la creación y administración de los archivos necesarios para la representación de este tipo de obras.

- Sección de Derechos de Variedades: encargada del cobro de los derechos de los espectáculos de variedades, así como la distribución de dichos derechos. Al igual que la anterior, esta sección habría de encargarse de la gestión de un archivo para los espectáculos de variedades.

- Sección de Derechos de Ejecución: cobraría los derechos de ejecución de música con procedimientos mecánicos y no mecánicos, en grandes y pequeños conciertos vocales e instrumentales y en toda clase de espectáculos.

- Sección de Derechos de Reproducción: creada para el cobro y administración de adaptación mecánica, de edición musical, de edición de li-

20 Como se verá después, al fundarse la SGAE en 1931, se crearon otros dos medios de comunicación con los socios: los Suplementos de la SGAE, de carácter informativo, y la revista El derecho de autor, de carácter más amplio, con informaciones acerca de la propiedad intelectual, el arte escénico, la producción musical, etc.

${ }_{21}$ Sociedad de Autores, Reglamento para la administración de la Sociedad de Autores, de 10 de septiembre de 1904 y reformado por Junta General de 29 de enero de 1907, Madrid 1908, Título 1. . 
bretos, adaptaciones cinematográficas, etc. Esta sección debía crear un archivo-museo de todas las reproducciones de obras de los individuos que forman la Sociedad ${ }^{22}$.

Dos figuras tuvieron una importancia primordial en el desarrollo de los primeros años de la Sociedad de Autores: el director-gerente y los representantes. Según el artículo 19 de los reglamentos de 1907 (que establecieron sus funciones) el director-gerente era el apoderado de la Sociedad «en todos los asuntos que constituyen el objeto social, pudiendo ostentar los derechos en juicio y fuera de él. Además representa a los autores y compositores asociados ante las autoridades y las empresas teatrales. Es el responsable de todos los servicios de la administración de la Sociedad, de ordenar los pagos, de facilitar a los socios los datos necesarios y liquidaciones, de intervenir en los contratos de traducción y representación de obras españolas en el extranjero, y de las extranjeras en lengua castellana, proponer a la junta general el nombramiento o la separación de empleados o representantes, publicar el boletín de la Sociedad, y no tiene voto en las juntas». Los reglamentos de 1922 formularon una nueva obligación para el director-gerente: la de presentar el presupuesto anual de gastos e ingresos en la obligada reunión de la primera quincena de enero (artículo 41). Como puede observarse, el papel del director-gerente era la clave de la coordinación interna de la Sociedad, pues en la realidad, era él quien llevaba el peso de la misma. Entre los directores-gerentes de la SAE estuvieron Carlos Arroyo, Antonio Fanosa y sobre todo, Emilio Sánchez Pastor, que permaneció en el cargo durante muchos años.

Los representantes eran particulares que, a cambio de un porcentaje, actuaban en nombre de la SAE en distintas circunscripciones territoriales, generalmente provincias, aunque con frecuencia, un representante podía ocuparse de varias provincias (en función de las circunstancias teatrales de cada localidad). Sus funciones las especificó el artículo 13: recaudar los derechos de autor y conservarlos hasta su entrega; recaudar en iguales condiciones el importe del alquiler del material de orquesta y derechos de ejecución según tarifas y contratos, rindiendo cuentas mensualmente; cumplir con las instrucciones de la dirección-gerencia; avisar de la llegada de las compañías a su localidad; velar porque se cumplan las condiciones en que el autor concedió el permiso para estrenar su obra; llevar un re-

22 Sociedad de Autores, Reglamento del régimen interior de la Sociedad de Autores. Organización de las secciones, Madrid 1922, Capítulo 1. , artículos 2. $, 4 .^{\circ}, 7 .^{\circ}$ y $10 .^{\circ}$. Cada archivo de sección estaría dirigido por un comité de cinco socios. Las secciones quedaban obligadas a celebrar juntas generales anualmente. 
gistro de las obras estrenadas en su localidad; remitir en los primeros cinco días de cada mes las relaciones de las funciones verificadas en el anterior, las de alquileres de material de orquesta y las de pequeño derecho con los programas correspondientes al mismo; remitir los fondos recaudados en las poblaciones donde hubiere sucursal de Banco de España por transferencia a la cuenta corriente de la SAE. Los representantes podían delegar en personas que les auxiliaran en localidades y pueblos más pequeños, según quedó acordado en la Junta General de enero de $1917^{23}$. La forma de actuar les era dictada a los representantes desde las páginas de las publicaciones de la Sociedad de Autores por medio de circulares. Se prestó especial atención, como es lógico, al cobro de los alquileres del archivo musical para lo cual se señaló un procedimiento específico: «Los señores representantes, en cuanto llegue a su localidad una compañía de zarzuela con material de orquesta, deben exigir la presentación del contrato de alquiler de archivo; en sus cláusulas verán estipuladas la cantidad que el arrendatario se ha comprometido a abonar por este servicio y deben exigir su importe sin contemplaciones de ninguna clase cobrando diariamente o por funciones, según conste en el referido documento. Algunos empresarios y directores de compañía, para burlar la buena fe de los representantes de la SAE, suelen pretender rebajas en los precios del alquiler de archivo afirmando que tiene concesiones especiales de esta dirección o de las sucursales de Barcelona y Valencia y que viene pagando menos de lo estipulado en todas las poblaciones sin protesta por parte de la sociedad. Esto no es exacto nunca y contra tales invenciones deben estar prevenidos nuestros representantes... ${ }^{24}$. Si el director-gerente era el coordinador de la Sociedad de Autores, los representantes eran sus elementos principales de trabajo, los que mantenían la extensa red de la SAE, un extensa red que era el fundamento de la Sociedad. Entre los representantes había personas de todo tipo, desde los que defraudaban a la SAE llegando a acuerdos con los empresarios teatrales hasta los que eran objeto de agresiones por parte de alcaldes y empresarios ${ }^{25}$.

Muy pronto la Sociedad alcanzó un desarrollo tan importante fuera de Madrid, que se decidió suprimir la representación de Barcelona, para constituir una sucursal que funcionara por si misma y que controlara a su vez las representaciones de las provincias cercanas. Al frente de ella se hallaba Marcos Jesús Bertrán ${ }^{26}$. Más adelante se constituyó otra sucursal en Valencia.

\footnotetext{
23 La Propiedad Intelectual, febrero de 1917.

Boletín Oficial de la Sociedad de Autores Españoles, octubre de 1904.

La Propiedad Intelectual, febrero de 1918 (Memoria y Acta de la Junta anual).

Boletín Oficial de la Sociedad de Autores Españoles, septiembre de 1905.
} 


\section{LOS DESAFIOS DE LA SOCIEDAD DE AUTORES ESPAÑOLES}

La Sociedad de Autores tuvo que enfrentarse a muchas dificultades relacionadas con su campo de acción. Evidentemente, algunas de ellas son muy concretas y nos dirían poco acerca del mundo del espectáculo de principios de siglo. Sin embargo, hay una serie de cuestiones, de carácter más general, que pueden ayudarnos a entender los grandes problemas que afectaban a los autores y compositores del momento. Uno de estos grandes asuntos fue el de las adaptaciones al cine tanto de obras de teatro, como de novelas o zarzuelas. Para los pioneros del nuevo arte suponía una tentación llevar al celuloide los grandes éxitos de otros géneros, tratando de explotar la rentabilidad económica obtenida en otros foros. Dado que la legislación al respecto no era clara, y que además a principios de siglo el cine aún se hallaba en sus primeros momentos, resultaba muy difícil el control de las adaptaciones fraudulentas. Desde muy pronto, quizá previendo las posibilidades del nuevo arte, la SAE tomó cartas en el asunto y estuvo pendiente de las apropiaciones indebidas. Una de las tendencias más fuertes del naciente cine español fue, precisamente, la de filmar zarzuelas, que para mayor paradoja, se veían con fruición en plena época del cine mudo. Una de las primeras denuncias de la SAE se realizó contra el pionero del cine español Fructuoso Gelabert, quien con su película Mala raza, había sido acusado de tomar el argumento de una obra de Echegaray (De mala raza) sin el pago de los correspondientes derechos. La película había sido estrenada en la Sala Argentina, de Barcelona, en abril de 1913. Juan Eugenio Morant, representante de la Sociedad, llevó a los tribunales a Gelabert, pero la SAE perdió el juicio, pues los jueces decían no haber encontrado en las declaraciones de los testigos las suficientes similitudes entre la obra y la película como para hablar de plagio. Esta sentencia fue muy censurada, incluso en el extranjero, donde la revista más importante en estas materias, Le droit d'auteur, denunció la incongruente decisión de los jueces ${ }^{27}$. Fueron muchos los casos de impago de derechos de autor para las adaptaciones cinematográficas. Hasta el mismo Benito Pérez Galdós se vio afectado por ello cuando se descubrió una copia filmada de su novela Doña Perfecta. Galdós, que había cedido los derechos de reproducción cinematográfica de sus obras a otra compañía, se vio forzado a proceder contra este intruso ${ }^{28}$.

Junto al cine, el desarrollo de los espectáculos de variedades fue otra de las formas de ocio que recogieron la atención de la Sociedad. La SAE

27 La Propiedad Intelectual, noviembre de 1914 y septiembre de 1916.

28 La Propiedad Intelectual, marzo de 1919. 
había nacido sobre todo para la protección del autor y del músico de zarzuela, ópera o teatro, sin embargo, la regulación de novedades musicales como el cuplé supuso todo un desafío ${ }^{29}$. La popularidad de este género musical condujo a que se difundiera en multitud de locales y, si bien en los más famosos era posible la labor de fiscalización de la SAE, en los de menor categoría resultaba imposible pues los empresarios no publicaban los programas y además: «Muchas de las cupletistas, de acuerdo con los dueños de los salones, cafés concierto y music-halls donde trabajan, alegan que los couplets que cantan no son de su propiedad y, por lo tanto, no tienen que pagar por ellos derecho alguno. Esto, en la casi totalidad de los casos, es absolutamente inexacto, como puede comprobarse en estas oficinas por las reclamaciones que nos dirigen los legítimos autores de esas piezas» ${ }^{30}$. Los cuplés habían pasado al acervo popular, el público deseaba oírlos en el escenario y el empresario estaba dispuesto a complacerlo, pues veía en ello un filón de primera magnitud. Las artistas, deseosas de imitar el camino ascendente a las famosas del género, estaban dispuestas a transigir con las demandas de unos y otros, pese a que alguien tuviera la exclusiva de dichas canciones. Tratando de paliar tantos desmanes, la SAE se propuso realizar un catálogo de cuplés para reordenar la situación, aunque de poco sirvió ${ }^{31}$.

Otra de las grandes preocupaciones de la SAE fue el cobro de los derechos de autor en America. La dificultad de proceder en este sentido ya había sido denunciada por los editores de libros, quienes se veían directamente afectados por la proliferación en América de copias fraudulentas de obras de autores españoles. La venta en América de estas ediciones, que tenían un precio inferior porque no pagaban derechos al autor, fue un problema realmente importante no sólo por el volumen del mismo, sino por la dificultad de controlarlo. España no tenía convenios acerca de la propiedad intelectual con todos los países de América, aunque desde luego, se fueron firmando en la primera veintena del siglo $\mathrm{xx}$. Mientras que los editores trataron de enviar reoresentantes o establecer sucursales en América para poner coto a estas estafas ${ }^{32}$, la Sociedad de Autores tomó sus propias medidas. Trató de arrendar el cobro de los derechos en

\footnotetext{
29 Vid. de S. Salaün, El cuplé (1900-1936), Madrid 1990.

30 Boletín Oficial de la Sociedad de Autores Españoles, marzo de 1905.

${ }^{31}$ Boletín Oficial de la Sociedad de Autores Españoles, marzo de 1905 (denuncias) y marzo de 1906 (catálogo).

32 La información sobre la situación del mundo editorial español en América se la debo a Ana Martínez Rus, la cual me ha permitido la consulta de su memoria de licenciatura titulada La proyección editorial en Hispanoamérica en el primer tercio del siglo XX. Madrid 1998.
} 
países como Méjico, aunque, al parecer, este proyecto no siempre salió como los miembros de la SAE deseaban, pues su éxito dependía demasiado de la honradez y solvencia de su corresponsal americano. Otra de las propuestas fue la negociación con teatros concretos, como se hizo con dos teatros de Buenos Aires. Por otra parte, algunas compañías españolas de gira por América se comprometían a pagar a su vuelta la parte correspondiente a los derechos de autores y compositores. Así solía hacer, por ejemplo, la compañía teatral de María Guerrero y su marido Fernando Díaz de Mendoza, a quien la SAE incluso llegó a nombrar su representante en Argentina durante 1912. Lo mismo sucedía con la compañía de Tirso Escudero, famoso empresario del mundo del espectáculo que en la temporada 1902-1903, y a la vuelta de su gira por Argentina, llegó a ingresar en las cajas de la SAE la cantidad de 12.630 pesetas en concepto de derechos devengados por la representación de obras de autores asociados ${ }^{33}$.

Las relaciones con los empresarios constituyeron, evidentemente, el centro de atención de la Sociedad. Ya los Estatutos de 1901, en su artículo $5 .^{\circ}$, establecían que «ningún autor ni maestro podrá formar parte de esta junta directiva mientras sea empresario o director artístico de teatros». De esta forma, quedaban claramente diferenciadas las esferas el autor y del empresario. La Sociedad regulaba sus tratos con los empresarios de teatro por medio de un contrato que firmaban el empresario en cuestión y el representante de la $S A E$, en el que se especificaba el aforo del teatro, la sala de baile o el salón de conciertos. El representante estaba obligado a mostrar al empresario las tarifas que cobraba la SAE por cada tipo de espectáculo. Las categorías fueron diferentes a lo largo del tiempo, pues a medida que se desarrollaban distintos tipos de ocio y evolucionaban las formas de esparcimiento, la clasificación se iba diversificando. En 1919, cuando ya se había estabilizado un tanto esta evolución, la Sociedad reorganizó dichas categorías que quedaron establecidas de esta forma: varietés; music-halls; cabarets, thétangos (sic) o análogos; cafés de segundo orden y bares; y, por último, bailes con entrada de pago ${ }^{34}$. Además de los pagos correspondientes por derechos de representación, de ejecución o al alquiler del archivo musical, el empresario tenía que abonar lo que se llamaba la «butaca de autor», que era la parte que pagaban los empresarios a la SAE en función del precio de las entradas. Lo recaudado por este concepto iba

33 Boletín Oficial de la Sociedad de Autores Españoles, octubre de 1903.

34 La Propiedad Intelectual, febrero de 1919. 
destinado al Montepío. Cuando el pago no se producía, el representante podía acudir a las autoridades (alcalde o gobernador civil) y debía poner en conocimiento del empresario defraudador que a partir de ese momento le quedaba totalmente prohibido todo el repertorio de la SAE y el de las sociedades extranjeras con las que ésta había establecido acuerdos.

Los empresarios teatrales se oponían a menudo a las decisiones y tarifas impuestas por la SAE, a la que cada vez veían con más capacidad de presión dado que ya en la segunda mitad de los años diez casi monopolizaba el alquiler de archivos musicales. Para enírentarse a eila con más fuerza decidieron fundar la Asociación de Empresarios de Espectáculos, sociedad que quedó constituía el 26 de abril de 1917, con domicilio social en Madrid, calle Marqués de la Ensenada. Sin embargo, y pese a que tenían razones para temer la capacidad de la Sociedad de Autores Españoles, entre los empresarios había comportamientos claramente abusivos. La revista La Propiedad Intelectual nos describe algunos de sus métodos: «...cuando a manos del empresario llega una obra que le gusta, llama al autor y le dice que es preciso hacer un arreglo de tales o cuales escenas, y que como él se encarga de estas modificaciones debe cobrar la mitad de los derechos. El autor que ha oído hablar al empresario, sabe ya que no es capaz de arreglar nada, que con dificultad escribe cartas a sus parientes y que la pluma no es el objeto que mejor manejan sus manos, como no sea para hacer cuentas. Pero no hay remedio: o se acepta la colaboración en el cobro o la obra no se pone en escena». También era frecuente la compra de una parte de la obra para sólo pagar la parte correspondiente de los derechos de autor mediante el procedimiento «...de llamar cuadros a los actos segundo y tercero de una obra que estos fines se declara dividida en dos actos solamente. La trampa ha sido manifiesta, porque una misma producción resultaba con dos actos en Madrid y con tres en provincias." O incluso, se solicitaba al autor la devolución del importe de un acto, aunque esta táctica no resultó exitosa. Para concluir, la revista nos relata un último caso de la picaresca empresarial: «También es frecuente que un empresario compre o tome una obra francesa o busque alguna de mediados del siglo anterior y se la entregue a un autor de su confianza para que la traduzca o arregle; este sencillo acto de encargar la adaptación o modificación del ejemplar de un comedia, crea, en el mundo de las malas costumbres, el derecho del empresario a cobrar la mitad de los productos de la obra» ${ }^{35}$.

35 La Propiedad Intelectual, septiembre de 1919. 


\section{PROBLEMAS INTERNOS}

Desde los primeros años de su funcionamiento, la SAE fue objeto de críticas tanto desde el exterior como por parte de los socios. No gustaron a muchos las disposiciones estatutarias ya citadas acerca del control de los contratos de los autores por parte de la Sociedad. Juan Pérez Gironés, por poner un ejemplo, escribió un folleto señalando los aspectos más censurables. Pérez Gironés había sido director del periódico sevillano El Baluarte y uno de los grandes luchadores contra el monopolio de las galerías dramáticas. Sin embargo, como miembro fundador de una Liga de Propietarios y Empresarios de Teatros, veía en la SAE una férrea dictadura que ataba a los autores en sus negociaciones con los dueños de los locales de espectáculos. El folleto llevaba un título muy explícito: La ganzúa literaria y la Sociedad de Autores. Estudio crítico de los procedimientos administrativos de dicha sociedad en relación con la Ley de Propiedad Intelectual (Sevilla 1903). En sus páginas se criticaba tanto a la Sociedad como a la legislación sobre la propiedad intelectual (algo no muy extraño en la época, por cierto). La publicación de Pérez Gironés fue una de las manifestaciones de esas críticas que también se estaban produciendo en el interior de la SAE. La publicación oficial recoge parte de esas denuncias: «...que los socios administrados están siendo objeto de indigna explotación por algunos de sus compañeros, que no inspira a todos una confianza absoluta la gestión de la junta directiva, y que existen ocultas influencias para anteponer los intereses de determinados autores a los de otros, injustamente postergados. $Y$ por si todo eso no fuera poco aún, hasta se ha insinuado la amenaza de privarnos del derecho que nos asiste para autorizar o prohibir a representación de nuestras obras teatrales, que sería tanto como privarnos de su propiedad" ${ }^{36}$. Por otra parte, se inició una gran campaña de prensa en contra de la SAE, atacando la gestión de la Junta directiva y, en particular, a Sinesio Delgado. Aparte de posibles arbitrariedades de la Sociedad, también habría que considerar que detrás de esta campaña de prensa se movían muchos intereses económicos afectados por la creación de la Sociedad de Autores. A tal extremo llegó la situación que Sinesio Delgado, muy apenado por la desconfianza que hacia su gestión económica habían manifestado algunos socios, presentó su carta de dimisión y se marchó de la SAE ${ }^{37}$. En mayo de 1904 presentó la dimisión el resto de la Junta directiva.

Boletín Oficial de la Sociedad de Autores Españoles, octubre de 1903.

Boletín Oficial de la Sociedad de Autores Españoles, febrero de 1904. Delgado, tratando de dejar limpio su nombre, publicó en su libro Mi teatro el estado de cuentas de la Sociedad y sus actividades como secretario. 
Superados estos primeros tiempos, la Sociedad se fue asentando en el panorama público español y su existencia comenzó a ser común en los debates sobre cualquier asunto relacionado con la creación artística. Hubo momentos puntuales especialmente sensibles, sobre todo cuando Jacinto Benavente solicitó su salida de la Sociedad. La SAE consideraba fundamental la afiliación de todos los autores, pero sobre todo de los más conocidos y de los más rentables, pues ahí se hallaba uno de los pilares de su fuerza. Cuando Benavente planteó la cuestión de su independencia, entre enero y febrero de 1918, la Sociedad ya estaba sólidamente asentada, pero el hecho de que Benavente fuera nada menos que su presidente honorario se consideró un golpe muy fuerte. Benavente arguyó críticas de otros autores como motivo de su marcha, aunque también se encontraban detrás intereses puramente económicos. La SAE manifestó los perjuicios que esta actitud podría traer consigo: «Porque la verdad, si los autores triunfadores y gloriosos niegan su concurso a los generosos movimientos de fraternidad y no han de auxiliar, en las circunstancias difíciles, con su prestigio y su poder, con su consejo y su experiencia, a cuantos han menester su ayuda por pobres, por débiles, por menos afortunados o por viejos, convengamos en que se les quita al triunfo personal y a la gloria muy nobles y puros laureles» ${ }^{38}$.

A comienzo de los años veinte, la Sociedad de Autores contemplaba cómo surgían en el serio del mundo artístico intentos de organización sindical. La publicación oficial La Propiedad Intelectual dio a la luz artículos de reflexión acerca de lo que llamaba «sindicalismo intelectual» en un tono marcadamente crítico. A la luz de la experiencia de la propia SAE, resulta curioso leer comentarios como éste: "La Junta que nos precedió tuvo que luchar con la formación de los sindicatos de cuantos elementos integran la vida del teatro, que aun siendo legítimas sus aspiraciones, dificultaban el desarrollo normal de estos negocios y, por consecuencia, en perjuicio evidente de nuestros intereses" ${ }^{39}$. Más acerbas se hicieron las críticas comentando el ingreso de la Sociedad de Artistas Franceses en la CGT: «Las asociaciones de intelectuales sólo deben federarse con sus afines, con aquéllas que están inspiradas en los mismos propósitos, que tienen los mismos intereses que defender y que están obligadas a mantener por propia conveniencia, en la mayor altura posible el respeto a la propiedad intelectual. Éste es el único sindicalismo que pueden aceptar los intelectuales del arte» ${ }^{40}$.

38 La Propiedad Intelectual, febrero de 1921.

39 La Propiedad Intelectual, febrero de 1921.

40 La Propiedad Intelectual, noviembre de 1921. 


\section{LA SOCIEDAD GENERAL DE AUTORES ESPAÑOLES (SGAE)}

La vieja Sociedad de Autores Españoles llegó a la década de los treinta con unos sistemas de funcionamiento que quedaban anticuados ante la complejidad que había alcanzado el mundo del espectáculo. Además, arrastraba problemas de difícil solución. Uno de ellos era la negativa de los empresarios a pagar la butaca de autor, cuyos fondos iban al Montepío de la SAE. Como medio de venganza, los empresarios se opusieron al estreno de cualquier obra de los hermanos Álvarez Quintero, al ser Joaquín presidente de dicho Montepío. Por otra parte, la SAE arrastraba un importante déficit económico desde hacía varios años ${ }^{41}$. Había llegado el momento, por tanto, de transformar la SAE en una organización más dinámica y que fuera capaz de dar acogida a las nuevas necesidades de sus socios. El impulsor de estas transformaciones fue Federico Romero quien, apoyado por la Junta directiva (Gregorio Martínez Sierra, Tomás Borrás, José Ramos Martínez, Carlos Arniches y los Álvarez Quintero), convocó a los autores en el nuevo local de la Plaza de Cánovas. La forma adoptada fue la de federación de cinco sociedades: la Sociedad de Autores Líricos (presidida por Federico Moreno Torroba), la Sociedad de Autores de Variedades (presidida por Ezequiel Endériz), la Sociedad de Derecho de Ejecución (presidida por el maestro Alonso), la Sociedad de Autores Dramáticos (presidida por Francisco Serrano Anguita), y el Montepío de Autores Españoles. Los empleados crearon su Montepío de Empleados de la Sociedad de Autores Españoles. Entre septiembre y octubre de 1934 se unió a la SGAE un nuevo miembro: la Sociedad de Autores Cinematográficos, con José Fons como director-gerente. Para la primavera del año siguiente (1935) la SGAE contaba ya con otra nueva federada: la Sociedad de Autores del Libro, la Prensa y el Arte (SALPA), fundada no hacía muchos meses. El presidente resultó ser Federico Oliver. Como vocales del llamado «grupo A» (Autores del Libro) salieron elegidos Tomás Borrás, Luis Astrana Marín y José García Mercadal. Los vocales del grupo B (Prensa) fueron Eduardo Zamacois, joaquín Aznar y José María Díaz Casariego y los del grupo C (Arte) Julio Moisés, Frutuoso Orduna y Joaquín Ruiz Vernacci.

La SGAE se dotó de nuevas publicaciones para dar a conocer sus actividades. Contó con una revista llamada El Derecho de Autor que pretendía ser una publicación para todas las personas interesadas en el mundo del espectáculo, tratando cuestiones generales acerca del teatro, el cine y

41 J. de Arozamena, La SGAE Conferencia leída el dia 17-3-1959 en la Facultad de Derecho de Madrid por el consejero delgado de la SGAE, Madrid 1961, pág. 21. 
la música. Por otro lado, salieron a la luz los Suplementos, que eran una publicación especializada para la profesión, con un tratamiento técnico de los distintos problemas que afectaban al sector.

Los problemas con los que se tuvo que enfrentar la nueva Sociedad fueron básicamente los mismos que afectaron a la SAE. Las dificultades con los empresarios se suavizaron gracias a los acuerdos parciales a los que se llegó en asuntos concretos, como por ejemplo el trato acordado para el pago de derechos de ejecución musical durante las proyecciones de películas (septiembre de 1932) ${ }^{42}$. Más tarde, en el otoño de 1934, la SGAE logró otro acuerdo con la Sociedad de Empresarios de Espectáculos de Madrid para el cobro de los derechos derivados de la «butaca de autor» en los teatros asociados a la organización empresarial, sancionando con la prohibición del uso del repertorio de la SGAE a los que se negaran a firmar este acuerdo ${ }^{43}$. También se reformaron los sistemas tarifarios de la SGAE para el cobro del alquiler del archivo musical. Para facilitar el pago a los empresarios, se decidió dividir las provincias españolas en cinco categorías en función de las cuales quedarían fijadas las tarifas ${ }^{44}$.

Los nuevos medios de comunicación obligaron a la Sociedad a plantearse la forma de gestionar el cobro de sus derechos. El cine, del que ya hemos hablado antes, volvió a forzar a la SGAE a pleitear por la utilización de canciones en las películas ${ }^{45}$. Eran éstos problemas derivados de la difusión del cine sonoro, problemas que sustituyeron a los del plagio de argumentos, solucionados en parte mediante el establecimiento de contratos-tipo entre los autores y las casas productoras de películas para obras originales y para adaptaciones ${ }^{46}$. La misma situación conflictiva se planteó con la radio, llegándose a firmar un acuerdo entre la SGAE y la Federación de radio-emisoras limitadas españolas ${ }^{47}$. Esta firma no evitó la aparición de otro problema: la utilización, por parte de los bares, de los aparatos de radio como medios de ambientación musical. La SGAE consiguió sentar precedente en el cobro de clerechos en esta materia cuando los tribunales fallaron a su favor tras la demanda presentada contra el Bar Pe-

42 Suplementos SGAE, septiembre de 1932.

43 Suplementos SGAE, octubre de 1934.

44 Suplementos SGAE, septiembre de 1932

45 Suplementos SGAE, diciembre de 1932. Por poner un ejemplo: Manuel Fernández Palomero, autor de la canción «Princesita», de la revista La Corte del Amor que tenía música del maestro Padilla pidió a la SGAE que demandara a Clara Paramount Films S.A. por haber utilizado dicha canción en la película Revista Paramount sin tener permiso para ello.

46 Suplementos SGAE, mayo de 1935.

47 Suplementos SGAE, noviembre de 1934 
reda, de Santander ${ }^{48}$. Por último, entre las diversas situaciones problemáticas novedosas que se le aparecieron a la SGAE señalaremos el conflicto suscitado con compañías teatrales como la dirigida por César Falcón, llamada Teatro Proletario. Este grupo teatral tenía asignado por la SGAE el pago de un $10 \%$ de la entrada en concepto de derechos por las obras que representaban, todas ellas de marcado contenido social: Al rojo, Los bajos fondos o albergue de la noche, Viernes Santos, Asia, La conquista de la prensa, La fuga de Kerenski, Un invento, Cyankali, El tren del escaparate y El monstruo. Las dificultades para conseguir que se pagasen tales derechos fueron considerables y la SGAE presionó fuertemente para conseguirlo, aunque el hecho de que muchos de los autores de estas obras que fueran extranjeros obstaculizó sus propósitos ${ }^{49}$.

Por lo que respecta a sus conexiones exteriores, la SGAE asistió como miembro de la federación internacional al VIII Congreso de Sociedades de Derechos de Autor, celebrado en Copenhague del 29 de mayo al 3 de junio de 1933 en el que se decidió que fuera en España, en Sevilla, donde tuviera lugar el décimo congreso. Esta reunión se celebró entre los días 5 y 12 de mayo de 1935 y tuvo uno de sus temas estrellas en los derechos de autor y el mundo del cine ${ }^{50}$.

48 Suplementos SGAE, julio de 1934.

49 Suplementos SGAE, mayo y junio de 1934.

50 Suplementos SGAE, mayo de 1935 , número monográfico dedicado al $\times$ Congreso Internacional de Sociedades de Autores y Compositores. 